\title{
Arte-Educação, Transtorno do Espectro Autista-TEA e possibilidades educativas
}

\author{
Art Education, Autistic Spectrum Disorder-TEA and educational possibilities \\ Educación artística, trastorno del espectro autista-TEA y posibilidades educativas
}

Recebido: 09/04/2021 | Revisado: 15/04/2021 | Aceito: 19/04/2021 | Publicado: 03/05/2021

\author{
Joel Cardoso \\ ORCID: https://orcid.org/0000-0002-6227-1282 \\ Universidade Federal do Pará, Brasil \\ E-mail: joelcardosos@uol.com.br \\ Neide Maria Fernandes Rodrigues de Sousa \\ ORCID: https://orcid.org/0000-0002-9129-0319 \\ Universidade Federal do Pará, Brasil \\ E-mail: nmfrs@ufpa.br \\ Francisco Pereira de Oliveira \\ ORCID: https://orcid.org/0000-0003-1327-8362 \\ Universidade Federal do Pará, Brasil \\ E-mail: foliveiranono@yahoo.com.br
}

\begin{abstract}
Resumo
O estudo teve como objetivo compreender a criança com Transtorno do Espectro Autista (TEA) na primeira infância (de zero a dois anos), refletindo sobre as possiblidades construtivas da Arte-Educação para o desenvolvimento e aprendizagem da criança. O TEA é caracterizado por dificuldades no desenvolvimento da linguagem, nos processos de comunicação e por déficits nos processos de socialização. A Arte pode proporcionar experiências e oportunidades de construção sensoriais, cognitivas e afetivas, e que dialoga com intervenções terapêuticas- pedagógicas na Educação de crianças atípicas com dificuldades na interação social e na comunicação. A pesquisa de abordagem qualitativa foi realizada por meio de entrevista narrativa com a mãe de uma criança com TEA. Os resultados sugerem que a criança desde os primeiros meses apresentou sinais do TEA como: dificuldade de amamentação, a ausência de contato visual, descontentamento nos momentos de toque, pouca reação a voz humana, fixação por objetos que pudessem ser girados e um padrão repetitivo de organização. A arte desperta, no bebê, múltiplas sensações: cria laços afetivos, promove o aconchego, estimula percepções sensoriais e movimento e precisam ser estimulados para essa expressão. Conclui-se que a criança com TEA na primeira infância, pode se beneficiar das possiblidades construtivas da Arte-Educação, como fator benéfico para o progresso interativo da criança.
\end{abstract}

Palavras-chave: Transtorno do espectro autista- TEA; Arte-educação; Desenvolvimento infantil.

\begin{abstract}
The study aimed to understand the child with Autistic Spectrum Disorder (ASD) in early childhood (from zero to two years), reflecting on the constructive possibilities of Art Education for the child's development and learning. TEA is characterized by difficulties in language development, communication processes and deficits in socialization processes. Art can provide sensory, cognitive and affective experiences and construction opportunities, and which dialogues with therapeutic-pedagogical interventions in the education of atypical children with difficulties in social interaction and communication. The qualitative research was carried out through a narrative interview with the mother of a child with ASD. The results suggest that the child showed signs of ASD from the first months: difficulty in breastfeeding, the absence of eye contact, discontent in the moments of touch, little reaction to the human voice, fixation by objects that could be rotated and a repetitive pattern of organization. Art awakens multiple sensations in the baby: it creates affective bonds, promotes coziness, stimulates sensory perceptions and movement and needs to be stimulated for this expression. It is concluded that the child with ASD in early childhood, can benefit from the constructive possibilities of Art-Education, as a beneficial factor for the child's interactive progress.
\end{abstract}

Keywords: Autism spectrum disorder - ASD; Art-education; Child development.

\section{Resumen}

El estudio tuvo como objetivo comprender al niño con Trastorno del Espectro Autista (TEA) en la primera infancia (de cero a dos años), reflexionando sobre las posibilidades constructivas de la Educación Artística para el desarrollo y aprendizaje del niño. TEA se caracteriza por dificultades en el desarrollo del lenguaje, procesos de comunicación y déficits en los procesos de socialización. El arte puede brindar experiencias sensoriales, cognitivas y afectivas y oportunidades de construcción, y que dialoga con intervenciones terapéutico-pedagógicas en la educación de niños atípicos con dificultades en la interacción social y la comunicación. La investigación cualitativa se realizó a través de una entrevista narrativa con la madre de un niño con TEA. Los resultados sugieren que el niño mostraba signos de 
TEA desde los primeros meses: dificultad para amamantar, ausencia de contacto visual, descontento en los momentos del tacto, poca reacción a la voz humana, fijación por objetos que podían rotar y un patrón repetitivo de organización. El arte despierta múltiples sensaciones en el bebé: crea vínculos afectivos, promueve la comodidad, estimula las percepciones sensoriales y el movimiento y necesita ser estimulado para esta expresión. Se concluye que el niño con TEA en la primera infancia, puede beneficiarse de las posibilidades constructivas del Arte-Educación, como un factor beneficioso para el progreso interactivo del niño.

Palabras clave: Trastorno del espectro autista (TEA); Educación artística; Desarrollo infantil.

\section{Introdução}

Como mestres, como educadores, como seres humanos, temos que, em consonância com a realidade que vivenciamos, entender as diferenças, as dificuldades individuais, as conjunturas socioeducativas. Temos que enfrentar a realidade (por vezes dura, adversa), mas, ao mesmo tempo, não podemos deixar de sonhar, de acreditar, de acolher, de incluir, para, juntos, unidos, construirmos um futuro melhor. É através dos outros, das pessoas que se relacionam conosco, dos modos como estabelecemos contatos com a realidade que nos circunda, que, desde sempre, nós nos tornamos aquilo que somos. Na atualidade, a inclusão de crianças com Transtorno do Espectro Autista (TEA) e as possiblidades construtivas pela via da Arte constituem-se como pontos de reflexão importantes para o desenvolvimento e aprendizagem das crianças com esse diagnóstico.

As pesquisas no campo do Transtorno do Espectro Autista- TEA têm avançado não somente no enfoque clínico, mas também do ponto de vista psicológico, educativo e artístico. Dessa forma, a Arte-Educação, enquanto um campo de estudo focaliza também as pessoas que apresentam um desenvolvimento neurotípico com déficits nas relações e comunicação e comportamentos estereotipados, na ideia de que a arte proporciona experiências e oportunidades de construção sensoriais, cognitivas e afetivas que dialogam com intervenções terapêutico-pedagógicas na Educação dessas crianças.

Assumindo esse último ponto de vista, essa pesquisa tem o objetivo de compreender a criança com Transtorno do Espectro Autista- TEA na primeira infância (de zero a dois anos), refletindo sobre as possiblidades construtivas da ArteEducação para o desenvolvimento e aprendizagem da criança. A Arte pode proporcionar experiências e oportunidades de construção sensoriais, cognitivas e afetivas, e que dialoga com intervenções terapêutico-pedagógicas na Educação de crianças atípicas com dificuldades na interação social e na comunicação.

A condição do Transtorno do Espectro do Autismo (TEA) consta nas categorias de Transtorno Autista, Transtorno Desintegrativo da Infância, Transtorno de Asperger e Transtorno Invasivo do Desenvolvimento sem outra especificação segundo o DSM-5 No mesmo documento, a pessoa com TEA é caracterizada com alterações importantes no neurodesenvolvimento, como déficits persistentes no comportamento, na interação social e na comunicação social e em diferentes contextos de desenvolvimento, além destes pode manifestar padrões restritivos e repetitivos de comportamento. Essas alterações caracterizam-se por dificuldade em estabelecer interações espontâneas com pares; carência da reciprocidade social e de comunicação não verbal e verbal, padrões repetitivos e restritos de comportamento, de curiosidade, atividades e rotina diária, ocorrendo uma confusão emocional nas mudanças de rotina (APA, 2013).

TEA é uma condição neurológica, de etiologia e níveis variados. Vem marcada por dificuldades no desenvolvimento da linguagem, nos processos de comunicação e por déficits nos processos de socialização. Tais déficits envolvem a comunicação verbal e não verbal, a linguagem corporal, o contato visual e a compreensão, além do uso estereotipado da fala ou de gestos e movimentos motores repetitivos (Bosa \& Hoher, 2009; Faro, Santos, Bosa, Wagner \& Silva, 2019; Rubim\& Matos, 2020)

Na primeira infância ou fase sensório-motora, o bebê apresenta evoluções no seu desenvolvimento, como melhora seus reflexos e a capacidade perceptiva motora, percebe os estímulos a sua volta. A partir do primeiro mês, sorri, e dos meses subsequentes consegue perceber e manipular objeto, segurar o pescoço, sentar, rastejar engatinhar, andar e falar, pegar, o entre outras ações (Brazelton, 2006; Papalia \& Olds, 2020). 
O TEA pode ser observado desde os primeiros anos da criança, os sintomas não são constantes, na maior parte de casos os desvios qualitativos no desenvolvimento são observados a partir dos 12 meses, contudo alguns bebês manifestam alterações com sinais perceptíveis desde os primeiros dias de vida (Homercher, Peres \& Smeha, 2020).

$\mathrm{Na}$ fase de 0 a 6 meses alguns indícios são significativos nos bebês; raramente choram, demonstram não gostar de companhia, apresentam pouco contato visual, dificuldade na amamentação, rigidez ou irritação quando pegos no colo, pouca troca de olhar com o cuidador, presta mais atenção a objetos do que a pessoas. No estágio de 6 meses a 12 meses são identificados alguns sintomas de TEA como: ausência do balbucio, tem gritos aleatórios, quando chamado não olha, falta de troca comunicativa, imitação ausente, pouca expressão facial e movimentos corporais, resistência a modificação na alimentação e não se engaja nas brincadeiras. Na etapa de 12 a 18 meses a criança apresenta ausência de gestos, como apontar um objeto, atraso na fala, problemas nas habilidades sociocomunicativas, carência de expressão facial, dificuldade de ampliar sua compreensão a situações novas e de comunicações; nas brincadeiras passa a enfileirar brinquedos ou objetos e se fixa em objetos que possa girar, assim também, apresenta resistência a mudanças na alimentação (Brasil, 2014).

Um conjunto de aportes legais e políticos asseguram os direitos das pessoas com TEA, e.g.: a Lei $\mathrm{n}^{\mathrm{o}} 12.764$ (de 27.12.2012) e instituiu uma Política Nacional de Proteção dos Direitos da Pessoa com Transtorno do Espectro Autista: a Política Nacional de Educação Especial DE 2020 202, o Plano Nacional de Educação de 2014 e a Lei Brasileira da Inclusão das Pessoas com Deficiência - LBI, Lei n ${ }^{\circ}$ 13.146, de 2015, também conhecida como Estatuto da Pessoa com Deficiência (BRASL, 2008; 2014; 2012-2015).

A Lei $\mathrm{n}^{\circ}$ 12. 764/2012 considera a pessoa com TEA uma pessoa com deficiência, com diversos direitos, entre eles a o diagnóstico precoce, ainda que não definitivo; o atendimento multiprofissional e à educação entre outros.

A educação de crianças que se enquadram nessa modalidade apresenta recursos e métodos específicos como o TEACCH, a comunicação Suplementar ou Alternativa (CSA) e o ABA. O TEACH usa estímulos visuais e audiovisuais para produzir comunicação em crianças não oralizadas, com a utilização de símbolos, no direcionamento de comportamentos ate a criança ser capaz de fazer de forma autônoma, contudo usando o recurso visual (Orrú, 2011).

Um modo de trabalhar a educação com o público alvo da educação especial, em específico às crianças com TEA, que não interfere nos métodos tradicionais, pelo contrário, auxilia as ações, é por meio da arte- educação. Pela arte as crianças podem se relacionar com o mundo físico e social e expressar afeto, cognição e motricidade. Pela arte, elas trabalham percepções, sensações, motricidade e constroem sentidos e vivencias de um mundo simbólico.

A aprendizagem infantil pela via da arte é mediada pelo lúdico, pela exploração da sensibilidade e da afetividade. Na Educação Infantil, o professor pode aprimorar as potencialidades perceptivas e as experiências artísticas das crianças, materializadas em ações como observar, desenhar, pintar, e dramatizar, tocar, ouvir e cantar. Nessa direção, as atividades artísticas ao enfatizar a relação tátil, visual e sonora com crianças autistas, estimulam as capacidades senso-perceptivas, melhoram a interação entre crianças e adultos e incentivam a diminuição de comportamentos estereotipados (Fernandes, Schlesener, Mosquera \& Teixeira, 2012).

A relação da criança com os objetos artísticos e culturais pode ocorrer pela arte-educação. E essa se efetiva objetivamente pelo toque, pela visão (desenhos, imagens, figuras), pela modelagem, pela musica, pela dramatização. Para Zanin (2014) a relação da criança com os objetos artísticos e culturais pode ser mediada pela arte-educação, sendo que a linguagem artística se dá pelo toque, pela visão dos desenhos e figuras, pela modelagem, pela musica e dramatização, entre outros.

Segundo Fernandes (2010) a arte pode auxiliar no processo de inclusão da criança com TEA. A dificuldade de comunicação e interação pode ser amenizada pela via da arte, seja pelas artes visuais ou pela musica. As linguagens artísticas por meio da estética, do lúdico, da imaginação e da criatividade estimulam o desenvolvimento e aprendizagem. Em específico 
as Artes Visuais, se utiliza de materiais, como tinta, areia, massa, cola papel e diversos estímulos táteis e visuais pode auxiliar a comunicação e interação das crianças com TEA.

A arte auxilia no processo de inclusão da criança com TEA. A dificuldade de comunicação e interação pode ser amenizada pela via da arte, seja pelas artes visuais ou pela musica. As linguagens artísticas por meio da estética, do lúdico, da imaginação e da criatividade estimulam o desenvolvimento e aprendizagem. Em específico, o trabalho com as Artes Visuais utiliza materiais, como tinta, areia, massa, cola papel e diversos estímulos táteis e visuais que interfere, na comunicação e na interação das crianças com TEA.

Os estudos supracitados atestam os benefícios e a importância no desenvolvimento da aprendizagem da criança com TEA, quando ocorre a inter-relação com as linguagens artísticas na intervenção terapêutica e educativa.

Diante do exposto, identifica-se a importância de se refletir sobre o desenvolvimento e aprendizagem da criança com TEA na primeira infância na sua inter-relação com a arte-educação, contribuindo com a produção de conhecimento na área. Desse modo, a pesquisa teve como objetivo compreender a criança com Transtorno do Espectro Autista- TEA na primeira infância (de zero a dois anos) e as possiblidades construtivas da Arte-Educação para o desenvolvimento e aprendizagem da criança.

\section{Metodologia}

"Suponho que entender não é uma questão de inteligência e sim de sentir, de entrar em contato. Ou toca ou não toca. Renda-se, como eu me rendi. Mergulhe no que você não conhece como eu mergulhei. Não se preocupe em entender, viver ultrapassa qualquer entendimento."

Clarice Lispector ${ }^{1}$

Sem descuidar dos aspectos humanos e subjetivos que caracterizam a pesquisa, como preconiza a citação, temos que nos predispor a conhecer, de sentir, de entender (passo a passo) e nos render às situações, para, por fim, entende-las. A perspectiva metodológica que conduziram esse trabalho caracterizou-se por abordagem qualitativa, do tipo estudo de caso; tendo como instrumento de levantamento de dados, a entrevista narrativa.

Na pesquisa qualitativa, buscamos a compreensão e o sentido apresentado pela mãe sobre o desenvolvimento e aprendizagem da criança com TEA, na sua relação com as linguagens artísticas. Para Minayo (2002, p. 21) a abordagem qualitativa possibilita a compreensão no cotidiano de fenômeno "[...] trabalha com o universo de significados, motivos, aspirações, crenças, valores e atitudes, oque corresponde a um espaço mais profundo das relações, dos processos e fenômenos". No estudo de caso, um tipo de pesquisa que usa geralmente dados qualitativos, fazemos um estudo e análise em profundidade de um único fenômeno ou objeto de pesquisa e deve ser considerado sua particularidade (André, 2013).

Aqui, o levantamento foi realizado por meio de entrevista narrativa com a mãe de uma criança com TEA. Na entrevista narrativa, a história emerge a partir das interações e diálogo entre entrevistador e participante. Observamos, conforme, Jovchelovich e Bauer (2002), as seguintes etapas: 1. Preparação (exploração do campo e formulação de questões exmanentes); 2. Iniciação (formulação do tópico inicial para narração); 3. Narração central (não interromper, fazer só encorajamento não verbal, narração e esperar para sinais de finalização); 4. Fase de perguntas (não emitimos opiniões ou formulamos perguntas sobre atitudes, não discutimos as contradições, tampouco fizemos perguntas como "por quê"? e 5. fala

\footnotetext{
${ }^{1}$ Lispector, Clarice. Perto do coração selvagem. Rio de Janeiro: Rocco, disponível em https://joaocamillopenna.files.wordpress.com/2019/08/lispector-pertodo-coracao-selvagem.pdf. Consulta em 03.04.2021.
} 
conclusiva (quando paramos a gravação; momento, imediatamente após a finalização da entrevista, em que nos permitimos buscar esclarecimentos e elaboramos as anotações).

Entrevistamos a mãe de uma criança com TEA. A criança tem, hoje, cinco anos de idade. É do sexo masculino e filho único. A mãe, casada, de 30 anos é professora da educação básica. Para preservar a identidade da mãe e filho optamos por usar nomes fictícios. À criança, chamamos de Lucas; e à mãe, de Andrea.

Após a entrevista, organizamos e interpretamos os dados por meio da análise de conteúdo, da seguinte maneira: pré análise, exploração do material e o tratamento dos resultados, a inferência e a interpretação (Cf. Bardin, 2011).

\section{Resultados e Discussão}

A narrativa materna teve como ponto de partida o pós-nascimento e se estendeu até a fase atual dos dois anos de Lucas, com destaque para a utilização da arte educação. As relações impulsivo-emocionais e sensório-motoras que evidenciam o TEA se fazem presentes desde o nascimento. Trata-se de uma fase incipiente na qual dificilmente as notamos. Como podemos identificar uma criança com comportamento atípico? Esta é uma pergunta que inevitavelmente surge no início da descoberta do indivíduo com autismo. Geralmente, ao observar o comportamento, começamos pela percepção de que a criança, dessa faixa etária, não corresponda àquilo que se convencionou chamar de normalidade.

Andrea, em sua narrativa, descreve sobre o nascimento até os três primeiros meses de Lucas. Discorre, ainda, sobre a avaliação inicial no hospital, a percepção enquanto uma criança recém-nascida, os primeiros contados, as interações mãe-bebê. Segundo ela, Lucas era um bebê muito quieto e externava uma certa intolerância ao contato, mas como era seu primeiro filho, ela considerava essas atitudes normais. Esta é, para os pais, para os profissionais, uma fase de descobertas, de aceitação paulatina. No seu depoimento, Andrea afirma ter percebido situações estranhas: a falta de contato visual de Lucas e um certo descontentamento no contato com o corpo da mãe; ele era pouco interativo; não apresentava reações emocionais mínimas ante os carinhos e sorrisos maternos e de familiares; pouca reação a voz materna. Esses sinais atípicos, não correspondem normalmente às esperadas, como características da interação mãe-bebê.

Lucas nasceu na cidade de Bragança-PA em 2015, pesou três quilos e duzentos gramas, com seus cinquenta e dois centímetros de grandeza. Esse acontecimento marcou para sempre a minha vida e de meu marido, era nosso primeiro filho, esperado e amado. O bebê foi considerado uma criança saudável.

Desde os primeiros dias de nascido Lucas demonstrou ser um bebê quieto, mas isso não causou estranhamento para mim, visto que achava normal. Com poucos dias de nascimento ele não conseguia ser amamentado de forma satisfatória: tinha preferência apenas por um só dos seios, o que dificultava a amamentação. Tal fato prejudicou a produção do leite materno que, com o passar dos dias, acabou e teve que fazer uso de alimentação. Eu como mãe, notava que não era um momento comum e tranquilo para o meu recém-nascido. Percebia no meu bebê um descontentamento nos momentos de toque, a ausência de contato visual dele comigo e pouca reação, tudo diferente que que achava comum na conexão entre mãe e bebê (Andrea).

As interações mãe-bebê ocorrem desde o nascimento. A organização comportamental inicial do bebê (sugar, agarrar, busca e apreensão do seio, busca de apoio etc.) estão relacionados ao contato com o corpo da mãe. O bebê, como parte de sua estrutura senso-perceptiva e motivacional, percebe outras pessoas e apresenta discriminação de certos estímulos. Entre elas, a voz humana feminina é a mais atraente. Dos estímulos visuais percebe a face humana, principalmente os olhos. A estimulação tátil, ocorrida pelo contato com o corpo da mãe (calor, balanço, conforto tátil) é algo positivo no esquema adaptativo para o bebê. Outro comportamento, o sorriso da criança é essencial na relação mãe-bebê (Hoehl \& Striano, 2010; Otta, 1994; Seidl de Moura, 2008). 
No caso da relação de Andrea e Lucas, a interação mãe-bebê eram mínimas e difíceis, havia uma percepção de que Lucas não aceitava de forma tranquila o contato com a mãe, a dificuldade de melhorar o reflexo de sucção e poucos contatos visuais e sorrisos.

A arte, aliada às intervenções terapêuticas e pedagógicas, se apresentou como possibilidades de construção de aprendizagens e habilidades para crianças com síndrome autista. As expressões faciais do bebê, os gestos, as aproximações ou afastamentos podem, desde cedo, ser objetos de observação e mediados pela linguagem artística. O uso das artes visuais e, principalmente, da música, a sonoridade da fala da mãe, a musicalidade melodiosa dessa interação, feita de forma natural, organizada, tudo isso, no conjunto, se constitui estrategicamente como uma metodologia específica e eficaz que pode facilitar a comunicação não verbal e as interações do bebê. Nessa fase da primeira infância, através da participação ativa do adulto, a arte desperta no bebê múltiplas sensações: cria laços afetivos, promove o aconchego, estimula percepções sensoriais e movimentos (Holm, 2007).

Andrea continua no seu relato oral sobre desenvolvimento de Lucas, agora com quatro meses e revela suas impressões:

A partir dos quatro meses as dificuldades de Lucas se tornavam mais explícitas, caracterizadas por não conseguir entender comandos básicos para a idade, se estivéssemos brincando com uma bola e a deixássemos cair a qualquer distancia de seu campo de visão entre outros brinquedos era quase impossível que ele conseguisse identifica-la, a não ser que o puséssemos frente a frente com ela. Lucas tinha alguns episódios de brincadeiras diferentes, sons repetitivos. Ele pouco sorria e me procurava pelo olhar, procuras que passavam despercebidas por mim.

O bebê apresenta gestos faciais e vocais que geram respostas previsíveis e esperadas para a mãe. Ela naturalmente entende como um sinal de que a criança deseja comunicar algo. Assim, se estabelece a díade mãe-bebê com comunicação do bebê sobre seu estado o que ocorre inicialmente por meio de recursos emocionais e afetivos e a mãe apresenta respostas previsíveis, o que aumenta a probabilidade dessa interação. Aos quatro meses a criança já desenvolve algumas habilidades inerentes à idade, como ver, ouvir, agarrar, tocar. O bebê manipula objetos de formas e materiais diferentes. Seu principal órgão de manipulação é a boca (Papalia \& Olds, 2020).

Um processo arte-educativo auxilia o desenvolvimento infantil. Através de atividades lúdicas, as crianças, pelo sentido, começam a vivenciar formas, cores e texturas. Para Holm (2007), os bebês, na sua relação com o mundo, trazem a arte dentro de si e necessitam apenas ser estimulados para interagir com essa realidade. Andrea relata que, a partir do primeiro ano de Lucas, as modificações foram ficando mais visíveis, mais explícitas tanto para ela quanto para família e isso foi despertando preocupações:

Após o seu primeiro ano isso as mudanças foram mais evidentes, percebidas principalmente no ato de brincar e nas atividades do cotidiano. Carlos gostava de enfileirar carrinhos e todos os tipos de brinquedos que tivessem cores e formatos semelhantes, pensava que era só uma criança que gostava de brincar de forma organizada. Ele tinha fixação por coisas que giravam tais como hélices, pneus de bicicleta e qualquer brinquedo que tivesse algo que pudesse ser girado; na linguagem ele emitia sons incompreensiveis e repetidos e percebia prazer em fazê-lo, o modo de sentar sempre com as pernas em W. Esses já eram notados por mim e por outras pessoas da família.

Klin (2006) afirma que é por volta dos doze aos dezoito meses que se tornam mais claras as dificuldades da criança com TEA, entre elas, o atraso no processo de verbalização da criança. A sequência destas fases é parte inerente ao desenvolver natural de toda criança, que, além do ato de olhar, pegar, se fazem presentes no processo de interação social. São relações emocionais que constroem o sujeito a partir do ambiente, das relações e dos cuidados dentro desta visão sócio interacionista, já 
que é a partir deste estágio sensório-motor que o indivíduo se conecta com a praticidade esperada para que a criança interaja efetivamente com o mundo ao seu redor.

Utilizar as artes, na perspectiva educativa e terapêutica é uma oportunidade de desenvolvimento e aprendizagem para criança com TEA. Ela pode apresentar padrões repetitivos de comportamento, como, por exemplo, o padrão de organizar e hipersensibilidade ao toque. A criança nessa situação necessita de estímulos por um período longo para facilitar o aprendizado. Além da música, as artes plásticas podem auxiliar no processo de sensibilização a determinados estímulos, ensinar a criança a tocar em tintas, serragem colorida e misturar cores entre outros são atividades que podem amenizar nos padrões repetitivos e de organização (Santos, 2015).

Com um ano e seis meses, as estereotipias de Lucas aumentaram e a família decidiu diagnosticá-la para procurar atendimento especializado. Essa busca começou com profissionais do município de Capanema e, em seguida, recorreu às ações executadas no Hospital Betina de Ferro, que tem um programa específico voltado ao diagnóstico e consequente tratamento das pessoas com Transtorno do Espectro do Autismo (TEA).

Inicialmente, procuramos uma pedagoga que trabalhava no Atendimento educacional Especializado-AEE de uma escola. Esta identificou características do TEA e nos orientou a consultar outros especialistas: fonoaudiólogo, médico, psicólogo. Fomos para Belém, onde fizemos as consultas no Hospital Universitário Betina de Ferro que tem um programa voltado para crianças com TEA e nosso filho teve o laudo com o Cid 10 F84.

Segundo Andrea, após o diagnóstico, foi orientada a fazer atendimento especializado. Hoje, Lucas frequenta uma clinica-escola especializada para crianças com TEA e, paralelamente, uma escola de educação infantil. A linguagem ainda está atrasada. As atividades de Lucas consistem em diversas brincadeiras e atividades individuais. As brincadeiras são blocos de montar, carrinhos, tampas de panelas, uma caixa d'agua (que ele apaixonadamente chama de "piscina"), momentos de pintura com guache entre outras coisas.

\section{Considerações Finais}

"As maiores aquisições de uma criança são conseguidas no brinquedo, aquisições que no futuro tornar-se-ão seu nível básico de ação real e moralidade."

Lev Vygotsky

Como docentes, não há como dissociar, na nossa prática cotidiana, na nossa experiência diuturna, Arte e Educação. São dois processos que (se em) caminham em uníssono, paralelamente. As artes constituem-se, por si mesmas, como uma porta de entrada, como possibilidade essencial e facilitadora para todas as instâncias didático-pedagógicas. Quanto ao tema da educação especial inclusiva, sempre caro e presente na nossa realidade, a Arte tem se mostrado como uma alternativa mais que prazerosa, eficiente, absolutamente necessária. Sem ela, as nossas intervenções pedagógicas ficam limitadas. Com a Arte não só ensinamos, mas, principalmente, aprendemos. Nada está mais próximo de nós do que a Arte. De alguma forma, ela sempre se faz presente, interferindo nos nossos modos de ser e estar no mundo. As artes visuais - em suas mais diversas modalidades orientam nossa percepção quanto à localização espacial. As artes musicais - canções, melodias, falas, oralidades, ruídos - nos sensibilizam e nos comovem. Elas nos fazem reconhecer sensações, estímulos, afetos, identificações, nos situando no universo que nos circunda. A arte sempre nos humaniza. Através dela, criamos, para além da nossa, outras realidades, exercitamos a nossa capacidade de reflexão, de abstração, de simbolização, de socialização. Através dela, nos (a) firmamos como seres 
humanos. Podemos, com as artes, crescer, atuar, nos harmonizar ou protestar com (ou contra) a realidade, enfim, personalizar e demarcar, melhor e mais prazerosamente, nosso lugar no mundo. A arte da palavra - falada, desenhada, escrita - é mola propulsora que nos encaminha na vida, desde a mais tenra idade. As palavras têm vida. Se faladas, têm a sua musicalidade, a sua entonação melódica, a naturalidade expressiva do seu ritmo, a sua magia afetiva. Daí, certamente, a importância da comunicação, da palavra elevada à sua categoria artística, na literatura, na poesia, nas canções etc. A arte da representação, consciente ou inconscientemente, se faz presente em todas conjunturas relacionais. Até mesmo a mãe, em sendo essa mãe, tem que representar, efetiva e convincentemente, para a criança, o papel de mãe.

No caso do nosso trabalho, versando especificamente sobre a temática da criança com TEA na primeira infância, acreditamos piamente nas possiblidades construtivas da Arte-Educação, como fator benéfico para o progresso interativo da criança. A prática nos encaminhou para a reflexão não só as questões conceituais e legais do Transtorno do Espectro Autista e a percepção materna dessa condição na primeira infância; mas também, trouxe para o debate as possibilidades terapêuticoeducativas pela via da arte educação.

O Transtorno do Espectro Autista, via de regra, apresenta sintomas típicos: déficit de interação e comunicação e comportamento estereotipado e a criança com TEA apresenta características diferenciadas no seu desenvolvimento (estágio sensório-motor) do desenvolvimento apresentam comportamentos evolutivos no âmbito dos reflexos, das percepções, sensações, da motricidade e afetividade características típicas de crianças com essa síndrome e pode ser identificado na primeira infância.

Nos resultados, a participante, em sua narrativa, relatou que desde os primeiros meses, o bebê apresentava comportamento diferenciado: era um recém- nascido quieto, a sucção no momento de mamar era difícil, na relação mãe-bebê, pouco interagia com olhar e se incomodava em ficar no colo. Após os quatro meses até um ano e seis meses, os comportamentos diferentes aumentaram: apareceram as estereotipias, os comportamentos perceptivos eram mais difíceis, assim como a dificuldade de interação com a mãe; após um ano foi realizado atendimento especializado e diagnosticado o TEA.

Nesse contexto, já foi possível trabalhar intervenções terapêutica educativa, com atendimento especializado. A arte educação vem sendo utilizada como aliada, como possibilidade interventivas e terapêuticas nas ações clínico educativo. A arteeducação, a partir de uma estratégia programada e organizada e considerando as características individuais da criança com TEA, pode ser utilizada como aliada aos recursos educativos e terapêuticos. Sabemos que a arte educação na primeira infância (fase sensória motora) envolve controle corporal, expressão afetiva e emocional, a percepção e dos sentidos, movimentos, experimentação, a criatividade. Essas ações com crianças são executadas junto com um adulto

O presente artigo indica uma pequena parte das possibilidades da arte educação em crianças com TEA. O tema sugere pesquisas mais avançadas, considerando a quantidade de crianças atípicas na sociedade atual e as possibilidades metodológicas da arte. Seu uso pode ocorrer tanto nos espaços terapêutico-educativo, como nas escolas de educação infantil onde tenha o público alvo da educação especial, em específico, crianças autistas.

Em suma, a arte-educação, inegável objeto de interação e conhecimento, manifestação primordial de vida, elo essencial para o entendimento das pessoas, atenuadora de diferenças, na sua interação com as ações clínicas e educativas possibilita ações e construção perceptivas sensoriais, cognitivas e afetivas para crianças atípicas, com estereotipias e dificuldades na interação social e na comunicação.

\section{Referências}

André, M. (2019). O que é um estudo de caso qualitativo em educação? Revista da FAEEBA - Educação E Contemporaneidade, $22(40)$, 95-103. 
American PsyquiatricAssociation - APA (2013). Tradução: Maria Inês Corrêa Nascimento et al, revisão técnica: Aristides Volpato Cordioli...et al.). Manual diagnóstico e estatístico de transtornos mentais: DSM. (5a ed.), Artmed.

Bardin, L. (2011). Análise de conteúdo. Edições 70.

Brasil. Ministério da Saúde. (2014). Diretrizes de Atenção a Reabilitação da Pessoa com Transtorno do Espectro do Autismo.

Bosa, C. A.\& Hoher, S. P. (2009). Autismo e Inclusão Possibilidades e Limites. In M.Gomes (Org.), Construindo as trilhas para a inclusão. Vozes.

Brazelton, T. B. (2006). O Grande Livro da Criança: o desenvolvimento emocional e do comportamento durante os primeiros anos. (9a ed.). Editorial Presença.

Camargo, S. P. H., \& Bosa, C. A. (2012). Competência social, inclusão escolar e autismo: um estudo de caso comparativo. Psicologia: Teoria e Pesquisa, 28(3), 315-324.

Faro, K. C. A., Santos, R. B., Bosa, C. A., Wagner, A., \& Silva, S. S. da C. (2019). Autismo e mães com e sem estresse: análise da sobrecarga materna e do suporte familiar. Psico, 50(2), e30080.

Fernandes, L. B. (2010). Ensino de arte no universo autista: um relato de Extensão da Faculdade de Artes do Paraná. (Dissertação de Mestrado). Faculdade de Artes, Universidade Tuiuti do Paraná, Curitiba, Brasil.

Fernandes, L B., Schlesener, A., Mosquera, C., \& Teixeira, R. M. (2012). Ensino de Arte e Autismo: Um Relato de Extensão. Revista Educação, Artes e Inclusão. 5(1).

Hoehl, S. \& Striano, T. (2010). Discrete Emotions in Infancy: Perception without Production? Emotion Review. 2, 132-133.

Holm, A. M. (2007). Baby - Art: os primeiros passos com a arte. Museu de Arte Moderna de São Paulo.

Homercher, B. M., Peres, L. S., Arruda, L. F. S., \& Smeha, L. N (2020). Observação Materna: Primeiros Sinais do Transtorno do Espectro Autista Maternal. Estudos e Pesquisas em Psicologia, 20 (2), 540-558.

Jovchelovich, S.\& Bauer, M. W. (2002). Entrevista Narrativa. In M. W. Bauer \& G. Gaskell (Orgs), Pesquisa qualitativa com texto, imagem e som: um manual prático (pp.90-113). Petrópolis: Vozes.

Klin, A. (2006). Autismo e síndrome de Asperger: uma visão geral. Revista Brasileira de Psiquiatria, 28 (1), 3-11.

Minayo, M. C.de S.(2002). Ciência, técnica e arte: o desafio da pesquisa social. In M. C.de S. Minayo, (Org.), Pesquisa social: teoria, método e criatividade (pp.9-29). Petrópolis: Vozes.

Orrú, S. E. (2011). Autismo: o que os pais devem saber? (2a ed.). Wak.

Otta, E. (1994). O sorriso e seus significados. Vozes.

Papalia, D. E., Olds, S. W. \& Feldman, R. D. (2020). O mundo da criança (8a ed.). McGraw-Hill.

Rubim, A. L \& Matos, D.C (2020). Comparação de tipos de pistas sobre o jogo funcional em crianças com transtorno do espectro do autismo. Research, Society and Development, 9 (7), e465974392.

Santos, M. C. A. (2015). Entre a vivência com educadores e a proposta com alunos com transtorno do espectro autista (TEA): estudo de atividades de arte com materiais de exploração sensorial. (Dissertação). Programa de Pós Graduação da Faculdade de Ciências Médicas da Universidade Estadual de Campinas, Campinas, SP, Brasil.

Seidl-de-Moura, M. L, Ribas, A. F. P, Seabra, K.da C., Pessôa, L. F., Nogueira, S. E., Mendes, D. M. L. Rocha, S. B \& Vicente, C. (2008). Interações mãebebê de um e cinco meses: aspectos afetivos, complexidade e sistemas parentais predominantes. Psicologia: Reflexão e Crítica, 21(1), 66-73.

Zanin, L. F. (2014). Novas tecnologias e processos de significação na arte e na educação. Anais do $23^{\circ}$ Encontro da ANPAP - "Ecossistemas Artísticos", Belo Horizonte, Brasil. 